\title{
Atypical Kawasaki disease in an early infant, a diagnostic challenge: Case report
}

\author{
Kaifi Siddiqui, Ayub Ansari, Ishaq Farooq, Sheeba Farooqui \\ From Assistant Professor, Department of Pediatrics, Hamdard Institute of Medical Sciences and Research, New Delhi, India
}

\begin{abstract}
A 4.5-month-old girl presented to us with continuous fever for 10 days and loose stools for 2 days. She received short courses of multiple oral antibiotics during this period however, was not relieved. Initial investigations were suggestive of urinary tract infection for which broad spectrum antibiotics were started. However, fever persisted even after $72 \mathrm{~h}$ of antibiotics. Blood counts showed persistently high total leukocyte count and increasing platelet count, along with high C-reactive protein. Consequently, a diagnosis of Kawasaki disease (KD) was suspected, which was supported by echocardiographic findings. After she received intravenous immunoglobulins, her fever subsided and lab parameters showed significant improvement. This case highlights an unusual presentation of KD in an uncommonly young age group without much clinical pointers except for persistent fever.
\end{abstract}

Key words: Kawasaki disease, Persistent fever, IVIG, Atypical Kawasaki disease

$\mathrm{K}$ awasaki disease $(\mathrm{KD})$ is an acute inflammatory vasculitis of small- and medium-sized arteries that can cause coronary artery weakening and aneurysm development in approximately $25 \%$ of untreated cases, with increased risks of cardiovascular complications and mortality [1]. Burns et al. [2-4] noted that $50 \%$ of children suffering from $\mathrm{KD}$ in India were more than 5 years of age. Possibly because it is being overlooked in infants and young children in whom the condition is being confused with viral exanthemata. Although one or multiple infectious triggers are most likely symptoms, the precise etiology is still unknown. $\mathrm{KD}$ is primarily a clinical diagnosis however, atypical or incomplete forms of $\mathrm{KD}$ are common (15-20\% of all patients) especially in children younger than 6 months [5], who also have the highest likelihood of development of coronary artery aneurysm as the long-term consequences [6] and resistance to therapy [7]. In such patients, laboratory and echocardiographic data can assist in diagnosis. Hence, it is recommended that any infant $<6$ months with fever $\geq 7$ days without explanation should undergo echocardiography to assess the coronary arteries. Here, we report the case of a 4.5-month-old child with an atypical KD, without much clinical clues, who developed aneurysm of the coronary arteries.

\section{CASE PRESENTATION}

A full term delivered, previously healthy, 4.5-month-old girl presented at our emergency department with a persistent fever

\section{Access this article online}

Received - 24 September 2021

Initial Review - 12 October 2021

Accepted - 21 October 2021

DOI: $10.32677 / \mathrm{ijch} . v 8 \mathrm{i} 11.3106$ for 10 days and loose stools for 2 days. Fever used to occur 3-4 times a day with a peak of $102-103^{\circ} \mathrm{F}$ (axillary). The child was apparently well and playful during afebrile period. Her oral intake was normal. She took incomplete course of oral amoxicillin with clavulanic acid, cefixime, cefuroxime during this period. On physical examination, she presented good general condition with $101.4^{\circ} \mathrm{F}$ body temperature, no signs of dehydration (capillary refill time $<2 \mathrm{~s}$ ) and mild perianal rash. Rest of the general and systemic examination was normal.

Before admission she had a very high value of C-Reactive Protein (CRP: $113.7 \mathrm{mg} / \mathrm{L}$ ), hemoglobin $(\mathrm{Hb}) 9.4 \mathrm{~g} / \mathrm{dL}$, white blood cell (WBC) count: $23,670 / \mathrm{mm}^{3}$ with $56.5 \%$ neutrophils, and platelet (PLT) count: $588,000 / \mathrm{mm}^{3}$. Blood culture report was awaited and malarial antigen report was negative.

On day 1 of admission blood tests showed a similar picture with persistent high value of CRP $(47.5 \mathrm{mg} / \mathrm{L}), \mathrm{Hb}: 9.3 \mathrm{~g} / \mathrm{dL}$, WBC count $24,800 / \mathrm{mm}^{3}$ with $60 \%$ neutrophils, and PLT count $784,000 / \mathrm{mm}^{3}$. The urine analysis showed plenty of pus cells (35- 40/HPF), marginally raised transaminases and renal functions were normal. Our patient being a female child of under 6 months of age with suggestive urine tests was representing high possibility of urinary tract infection (UTI) and started with inj. ceftriaxone and inj amikacin.

On day 3 of admission, the fever persisted with minimal variability; however, the CRP showed a falling trend $(38.3 \mathrm{mg} / \mathrm{L})$, with $\mathrm{Hb} 9.2 \mathrm{~g} / \mathrm{dL}$, WBC count $28,400 / \mathrm{mm}^{3}$ with $60 \%$ neutrophils, and PLT count $743,000 / \mathrm{mm}^{3}$. The urine analysis showed decrease in pus cells (16-18/HPF).

Correspondence to: Kaifi Siddiqui, Department of Pediatrics, Hamdard Institute of Medical Sciences and Research, Hamdard Nagar, New Delhi, India. E-mail: homealoned@yahoo.com

(C) 2021 Creative Commons Attribution-NonCommercial 4.0 International License (CC BY-NC-ND 4.0). 
On day 4, antibiotics were upgraded in view of partial response (decreased CRP and decrease in pus cell in urine.).

On day 5 , the fever decreased in intensity but remained well above the base line. The CRP again increased to $55.0 \mathrm{mg} / \mathrm{L}$, complete blood count showed a similar picture, with the only notable change being significant increase in PLT count to $803,000 / \mathrm{mm}^{3}$. Transaminases values were also increased (SGOT:

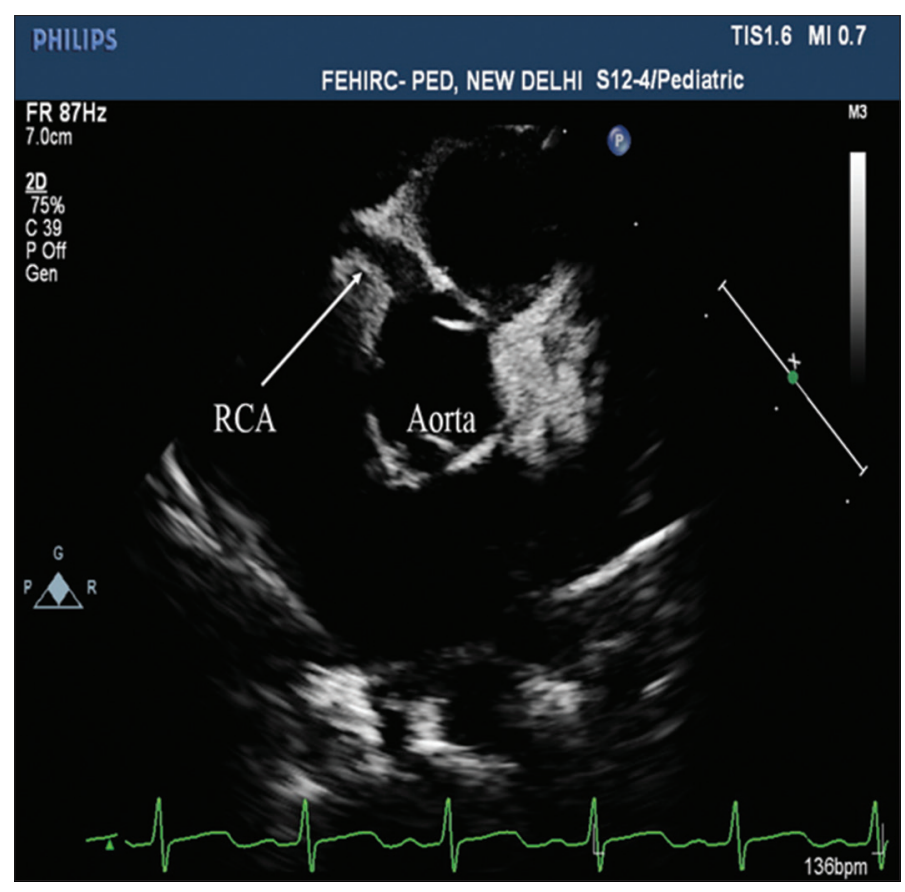

Figure 1: Transthoracic echocardiography. Parasternal short axis view showing aorta in cross-section and dilated, non-tapering right coronary artery. RCA: Right coronary artery

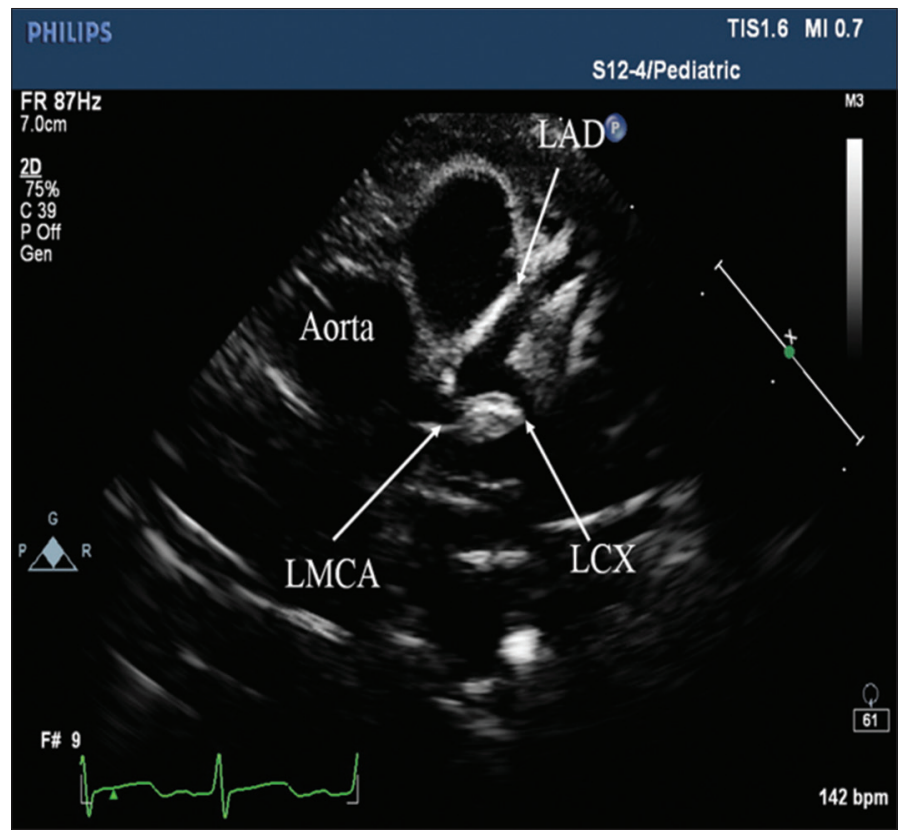

Figure 2: Transthoracic echocardiography. Parasternal short axis view showing aorta in cross-section with dilated left main coronary artery, left anterior descending coronary, and left circumflex coronary artery. LMCA: Left main coronary artery, LAD: Left anterior descending coronary artery, $L C X$ : Left circumflex coronary artery
106.5 U/L, SGPT: $151.9 \mathrm{U} / \mathrm{L})$. Initial blood culture and urine culture showed no growth.

Repeated detailed clinical examinations were not helpful and child showed no clinical signs suggestive of KD. Hence, in view of persistent fever and laboratory parameters (Raised CRP, WBC $>15,000$, elevated alanine transaminase levels, PLT counts $>4.5$ lakhs, and urine $>10 \mathrm{WBC} / \mathrm{hpf}$ ), an echocardiogram was performed.

Interpretation summary: Trace tricuspid regurgitation, trace pulmonic regurgitation, trace pericardial effusion, and dilated coronary arteries as mentioned in Figures 1-3. LMCA: $4.1 \mathrm{~mm}$ ( $\mathrm{z}$ score +6.9), LAD: $2.4 \mathrm{~mm}$ (Z score +4.2), LCX: $1.8 \mathrm{~mm}(Z$ score +2.5$)$, and RCA: $3.4 \mathrm{~mm}(Z$ score +7.7$)$. With the above findings the diagnosis of $\mathrm{KD}$ with medium-sized coronary artery aneurysm was made according to the American Heart Association criteria [6]. She received intravenous immunoglobulin (IVIG infusion of $2 \mathrm{~g} / \mathrm{kg}$ ) and high-dose oral acetylsalicylic acid (100 mg/kg/day).

Outcome and follow-up: After administration of IVIG and aspirin, the fever dramatically defervesced in the following $24 \mathrm{~h}$. The total leukocyte count dropped down to $15,000 / \mathrm{mm}^{3}$ and CRP was reduced to $18 \mathrm{mg} / \mathrm{L}$. After $48 \mathrm{~h}$ of afebrile period, the dose of aspirin was changed to $5 \mathrm{mg} / \mathrm{kg}$ and the child was discharged.

\section{DISCUSSION}

$\mathrm{KD}$ is an acquired heart disease most common in infants aged 6 months-2 years. It is challenging to make a diagnosis of incomplete KD, particularly in infants younger than 6 months with fewer clinical manifestations [7-9]. Ram Krishna et al. [9] studied the predictors of coronary artery aneurysm. They suggested that anemia, low albumin, elevated erythrocyte sedimentation rate (ESR), elevated CRP, and pyuria are the risk factors of coronary artery abnormalities. The most common complications of KD

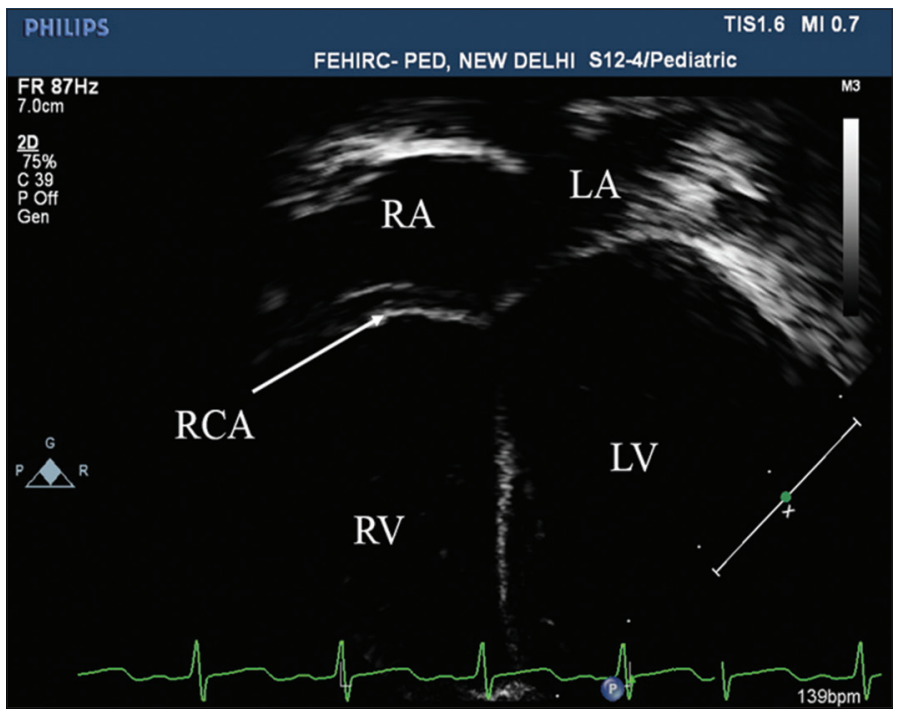

Figure 3: Transthoracic echocardiography. Apical four chamber view showing dilated right coronary artery in interventricular groove. RCA: Right coronary artery, RA: Right atrium, LA: Left atrium, LV: Left ventricle, RV: Right ventricle 
include coronary artery dilatation caused by coronary artery vasculitis and aneurysm [10-12]. Other complications include decreased coronary arterial compliance, myopericarditis, arrhythmias, ischemic heart disease, pericardial effusion, valvular regurgitation, myocardial infarction, and sudden cardiac death. Prompt diagnosis and administration of IVIG within 10 days, or ideally before day 7 of the disease, are mandated to reduce such cardiac complications [9].

Since diagnosing KD in infants younger than 6 months is difficult, any febrile infant who has fever for 7 days or more without other explanations, even without any clinical clues of $\mathrm{KD}$, should receive a blood analysis of systemic vascular response. If the ESR or CRP is elevated, echocardiography should be performed [10].

Unfortunately, in our case, the patient presented on $10^{\text {th }}$ day of fever without any supportive clinical findings of KD and the preliminary tests pointed toward UTI. The initial fall of CRP, decrease in pus cells in urine and relative decrease in fever spikes after the start of intravenous antibiotics led to further delay in clinching the diagnosis. Persistent increase in PLT count was one marker that helped us strongly suspect of KD [13]. Apart from medium sized aneurysm in coronary arteries, there were no other complications.

\section{CONCLUSION}

KD should be considered in infants $<6$ months even though the incidence is low in this age group. In such children, a significant proportion would not fulfill the diagnostic criteria as many would have "incomplete" and "atypical" forms of the disease and unfortunately this age group is most vulnerable to development of coronary artery aneurysm. Hence, it is recommended that any infant of age $<6$ months with fever for $\geq 7$ days without explanation should undergo echocardiography to assess the coronary arteries.

\section{REFERENCES}

1. McCrindle BW, Rowley AH, Newburger JW, Burns JC, Bolger AF, Gewitz M, et al. Diagnosis, treatment, and long-term management of Kawasaki disease: A scientific statement for health professionals from the American heart association. Circulation 2017;135:e927-99.

2. Kushner HI, Macnee R, Burns JC. Impressions of Kawasaki syndrome in India. Indian Pediatr 2006;43:939-42.

3. Kushner HI, Macnee RP, Burns JC. Kawasaki disease in India: Increasing awareness or increased incidence? Perspect Biol Med 2009;52:17-29.

4. Burns JC. Kawasaki disease update. Indian J Pediatr 2009;76:71-6.

5. Singh S, Agarwal S, Bhattad S, Gupta A, Suri D, Rawat A, et al. Kawasaki disease in infants below 6 months: A clinical conundrum? Int J Rheum Dis 2016;19:924-8

6. Newburger JW, Takahashi M, Gerber MA, Gewitz MH, Tani LY, Burns JC, et al. Diagnosis, treatment, and long-term management of Kawasaki disease: A statement for health professionals from the committee on rheumatic fever, endocarditis and Kawasaki disease, council on cardiovascular disease in the young, American heart association. Circulation 2004;110:2747.

7. Yeom JS, Woo HO, Park JS, Park ES, Seo JH, Youn HS. Kawasaki disease in infants. Korean J Pediatr 2013;56:377-82.

8. Park YW, Han JW, Park IS, Kim CH, Cha SH, Ma JS, et al. Epidemiologic study of Kawasaki disease in 6 months old and younger infants. Korean J Pediatr 2008;51:1320-3.

9. Ram Krishna M, Sundaram B, Dhanalakshmi K. Predictors of coronary artery aneurysms in Kawasaki disease. Clin Pediatr (Phila) 2014;53:561-5.

10. Ruan Y, Ye B, Zhao X. Clinical characteristics of Kawasaki syndrome and the risk factors for coronary artery lesions in China. Pediatr Infect Dis J 2013;32:e397-402.

11. Callinan LS, Tabnak F, Holman RC, Maddox RA, Kim JJ, Schonberger LB, et al. Kawasaki syndrome and factors associated with coronary artery abnormalities in California. Pediatr Infect Dis J 2012;31:894-8.

12. Kim DS. Kawasaki disease. Yonsei Med J 2006;47:75972.

13. Mbf S, Newburger JW, Disease K. Nelson Textbook of Pediatrics. $20^{\text {th }}$ ed. Philadelphia, PA: Elsevier; 2016. p. 1209-14.

Funding: None; Conflicts of Interest: None Stated.

How to cite this article: Siddiqui K, Ansari A, Farooq I, Farooqui S. Atypical Kawasaki disease in an early infant, a diagnostic challenge: Case report. Indian J Child Health. 2021; 8(11):394-396. 